\title{
IDENTIFICAÇÃO DAS ESPÉCIES ARBÓREAS DO VIVEIRO DO HORTO MUNICIPAL DE PRESIDENTE PRUDENTE - SP E QUAIS ESPECIES SÃO MAIS EMPREGADAS NA ARBORIZAÇÃO URBANA
}

Mariane Moura Andrade ${ }^{1}$

Natália Felisberto Diniz ${ }^{2}$

André Gonçalves Vieira ${ }^{3}$

\section{RESUMO}

A identificação botânica possui um papel fundamental tanto na perspectiva científica como para o manejo dos recursos naturais, à nomeação e identificação das espécies, é fundamental para reconhecimento de espécies diferentes. O presente estudo realizou a identificação das espécies do viveiro do horto municipal de Presidente Prudente - SP e a sua aplicação na arborização urbana. Sendo este de suma importância quando se pensa em identificações de espécies arbórea a fim de melhorar a arborização urbana, buscando espécies adequadas para cada área da cidade. Nesse trabalho foram utilizadas pesquisas e bibliografias, chaves dicotômicas e herbários digitais chegando a resultados de identificação de 84 espécies de plantas sendo 42 espécies nativas e 42 espécies exóticas. As espécies que são mais utilizadas na arborização urbana são: Oiti, Quaresmeira, Resedá, Aroeira Salsa, Acácia amarela, Alfeneiro, Ipê de Jardim, Ipê branco e amarelo, Magnólia, Flamboyant mirim, Pataca, Jambo, Pata de vaca. Observa-se que através da identificação das espécies do Horto Florestal, é possível saber quais espécies podem ser doadas e plantadas, servindo assim como base para futuros trabalhos de gestão do viveiro.

PALAVRAS-CHAVE: Botânica, espécies, arbóreas, arborização

\section{IDENTIFICATION OF THE NURSERY TREE SPECIES OF THE GARDEN CITY OF SAGE PRESIDENTE PRUDENTE - SP AND SPECIES WHAT ARE EMPLOYED IN MORE URBAN AFFORESTATION}

\footnotetext{
${ }^{1}$ Engenheira Florestal pela Universidade Tecnológica Federal do Paraná, Campus Dois VizinhosParaná e Pós-graduanda em MBA de Gestão Ambiental e Desenvolvimento Sustentável pela Universidade Centro de Ensino Superior de Maringá, Presidente Prudente- São Paulo, e-mail: enairamma@hotmail.com

${ }^{2}$ Engenheira Ambiental pela Universidade do Oeste Paulista, Presidente Prudente - São Paulo, email:natalia.ffdiniz@gmail.com

${ }^{3}$ Graduado em Ciências Biológicas - Bacharelado e Licenciaturapela Universidade do Oeste Paulista, Presidente Prudente - São Paulo, Mestrando em Geografia pela Universidade Estadual Paulista Júlio de Mesquita Filho, Presidente Prudente - São Paulo, e-mail:dre_goncalves@hotmail.com
} 


\title{
ABSTRACT
}

The botanical identification plays a key role in the scientific perspective as to the management of natural resources, the appointment and identification of species, it is essential to recognize different species. This study was conducted to identify the species of the nursery garden city of PresidentePrudente - SP and its application in urban forestry. Which is very important when thinking about identifications of tree species in order to improve urban afforestation, seeking appropriate species for each area of the city. In this study, we used surveys and bibliographies, dichotomous keys and digital herbarium reaching identification results of 84 plant species and 42 native species and 42 exotic species. The species that are most widely used in urban forestry are: Oiti, Quaresmeira, mignonette, Aroeira Salsa, Yellow acacia, Privet, Garden Ipe, Ipe white and yellow magnolia, mirim Flamboyant, Pataca, Jambo, cow Pata. It is observed that by identifying the species of the garden forest, it is possible to know which species can be donated and planted, thus serving as a basis for future nursery management jobs.

KEYWORDS: Botany, species, tree, trees.

\section{IDENTIFICACIÓN DE LA ESPECIE ÁRBOL VIVERO DE LA CIUDAD JARDÍN DE PRESIDENTE PRUDENTE- SP Y ESPECIES QUE SE TRABAJA EN MÁS FORESTACIÓN URBANO}

\begin{abstract}
RESUMEN
La identificaciónbotánicajuegaun papel clave enla perspectiva científica como a lagestión de los recursos naturales, elnombramiento y laidentificación de lasespecies, es esencialreconocerlas diferentes especies. Este estudio se realizó para identificar lasespecies de laciudadjardín de vivero de Presidente Prudente - SP y suaplicaciónenla silvicultura urbana. Que esmuy importante cuando se piensaenlasidentificaciones de lasespecies de árboles con elfin de mejorarlaforestación urbana, en busca de especiesadecuadas para cada zona de laciudad. En este estudio, hemos utilizado lasencuestas y bibliografías, claves dicotómicas y de herbarioalcanzar resultados de identificación digital de 84 especies de plantas y 42 especies nativas y 42 especies exóticas. Lasespecies que más se utilizanenla silvicultura urbana son: Oiti, Quaresmeira, reseda, Aroeira Salsa, acaciaamarilla, Privet, Jardínlpe, Ipemagnoliasblancas y amarillas, mirim Flamboyant, Pataca, Jambo, vaca Pata. Se observa que mediante laidentificación de lasespeciesdel Horto Florestal, es posible saber quéespeciespueden ser donados y plantados, lo que sirve de base para futuros trabajos de gestión de viveros.
\end{abstract}

PALABRAS CLAVE:Botánica, especies, árbol, árboles.

\section{INTRODUÇÃO}

As coletas e asidentificações botânicas possuem um papel central tanto do ponto de vista científico como para o manejo dos recursos naturais. A taxonomia, ciência relacionada à nomeação e identificação das espécies, é essencial no contexto do reconhecimento das diferentes espécies, e, portanto, serve de base para estratégias de conservação, por outro lado, é fundamental obter informações precisas quanto às espécies ocorrentes em determinada área, como forma de 
subsidiar as análises referentes à sustentabilidade do manejo florestal (ROTTA \& CARVALHO, ZONTA, 2008).

Espécies arbóreas destinadas a arborização urbana devem ter qualidade, pois isso irá refletir no melhor desenvolvimento das espécies e em menores interferências em ações futuras em relação ao meio, principalmente, como o uso indiscriminado de podas. É necessário que os esforços municipais não sejam reunidos somente no plantio e na manutenção, mas especialmente na produção de mudas para que a arborização de ruas cumpra com seus benefícios funcionais e estéticos (BIONDI et al. 2007).

Segundo Dantas e Souza (2004), delinear a arborização é imprescindível para o desenvolvimento urbano, para que o meio ambiente não tenha prejuízos, pois a arborização é um fator definitivo da sanidade ambiental, por haver influência direta sobre o bem estar do homem, em virtude dos múltiplos benefícios que proporciona ao meio, contribuindo para a estabilização climática, embelezamento das ruas, fornecendo alimento e abrigo à fauna, assim como favorece sombra e lazer nos parques, praças, jardins, ruas e avenidas das cidades.

O presente trabalho teve por objetivo a identificação das espécies arbóreasdo Horto Municipal de Presidente Prudente - SP, e identificar quais as espécies mais empregadas na arborização urbana da cidade.

\section{MATERIAL E MÉTODOS}

\section{1 ÁREA DE ESTUDO}

O estudo foi realizado no Horto Municipal da cidade de Presidente Prudente, situado na Secretaria de Meio Ambiente na Rua Altair Sena, 730, Jardim Jequitibás,

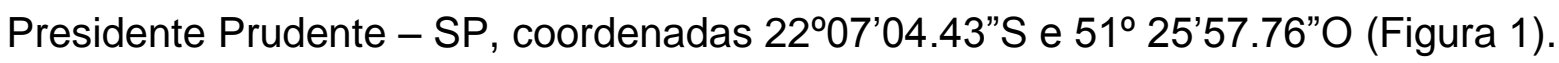


FIGURA 1 - Vista superior da área do Horto municipal.

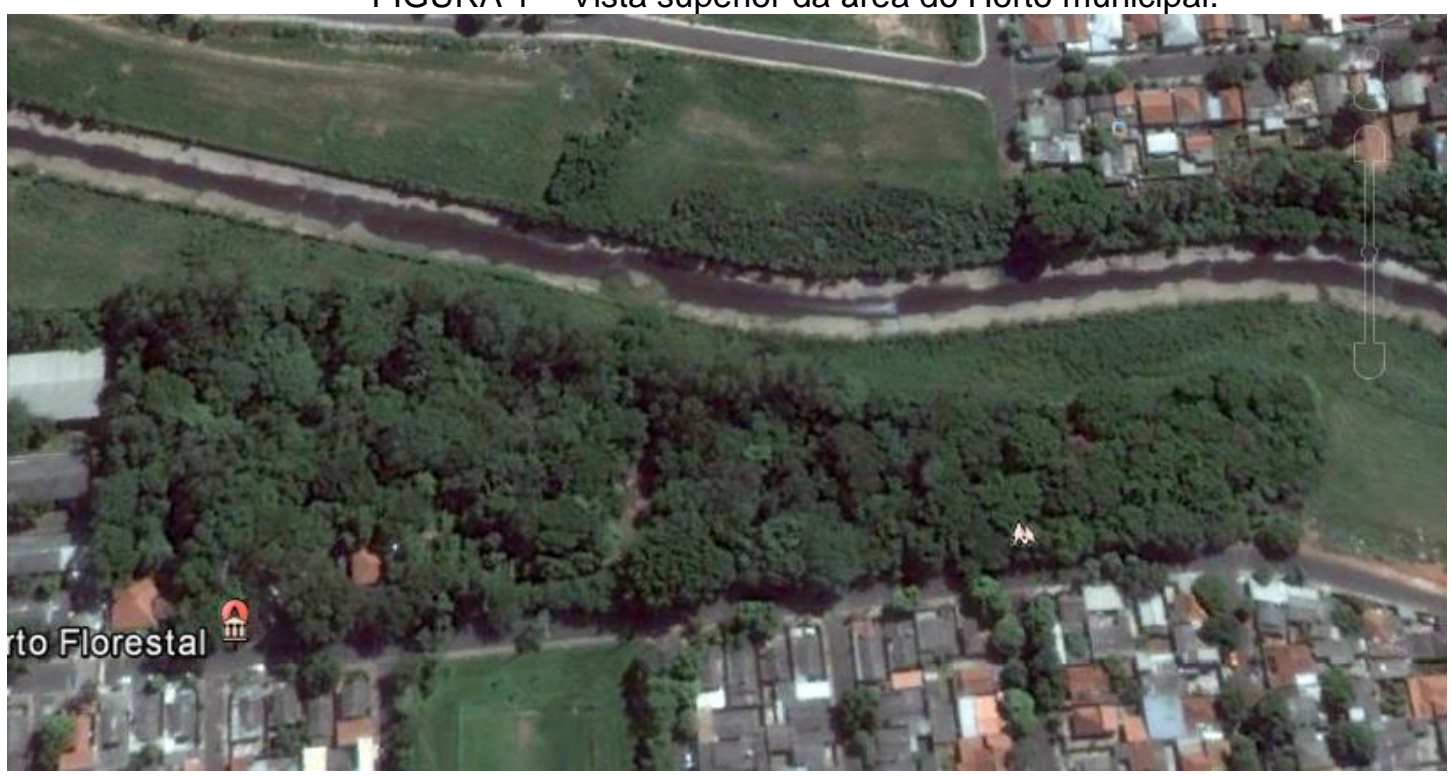

FONTE - Google Earth

O estudo foi realizado no Horto Municipal da cidade de Presidente Prudente, situado na Secretaria de Meio Ambiente na Rua Altair Sena, 730, Jardim Jequitibás,

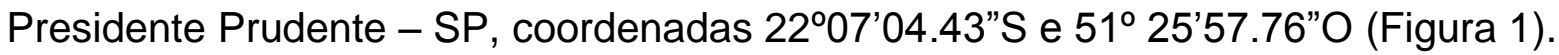

De acordo com Monteiro (1973), Presidente Prudente possui características climáticas de invernos secos com pouca precipitação, que sofre ação predominante dos sistemas polares, e verões chuvosos devido ao predomínio dos sistemas tropicais. Boin (2000) salienta ainda que: a precipitação anual na região varia entre 1200 e a 1500 mm, enquanto a temperatura média anual permanece acima de $22^{\circ} \mathrm{C}$.

A região possui características de vegetação Floresta Estacional Semidecidual. Estacional por apresentar duas estações do ano bem definidas (chuvosa e seca) e semidecidual por apresentar porcentagem de árvores caducifólias característico deste conjunto florestal. Assim a vegetação da bacia é entendida como Floresta Estacionária Semidecidual, contida na classificação fisionômico-ecológico da formação ecológica do Sudeste Paulista de acordo com Francisco (1989).

O Município de Presidente Prudente tem como característica de vegetação em zona rural de pastagens e vegetação arbórea esparsa, ficando o solo coberto em todas as épocas do ano (GOMES \&AMORIN, 2003). O mesmo está localizado na bacia hidrográfica do rio Paraná, tendo em seu território várias sub-bacias de pequenos e médios córregos com papéis importantes em sua configuração, e sendo drenados pelos córregos do Veado e do Cedro, pertencentes à bacia do rio Santo 
Anastácio; e pelo córrego da Onça e rio Mandaguari, que pertencem à bacia do rio do Peixe. A cidade apresenta-se levemente ondulada com ocorrência contínua de colinas, na grande maioria com divisores constituídos por cursos d’água.

\section{MÉTODO DE ANÁLISE}

Para a identificação das espécies do Horto foram realizados registros fotográficos e coletas de folhas das espécies com tesoura e foram armazenadas em sacos plásticos transparentes e lacradas com grampeador e levadas para sala de estudos do horto para realização da identificação das mesmas com auxilio de pesquisas bibliográficas, chaves dicotômicas e herbário digital.

Após a identificação foram feitas catalogações das espécies em forma de cartilha onde foram colhidas informações como: nome popular e científico das espécies, altura máxima que a espécie pode chegar período de floração, quanto à luminosidade se esta se adapta ao sol ou sombra, e se a espécie é exótica ou nativa.

Quanto à empregabilidade desta em meio urbano, está foi feita através de pesquisas de banco dados coletados junto à secretaria que registra qual espécie foi plantada pelo município ou doadas a moradores, quantidades e endereços, 0 levantamento foi realizado no período do mês de abril de 2014 a abril de 2015.

Foram identificadas todas as espécies arbóreas, posteriormente classificadas por nome cientifico, nome popular, altura, floração, luminosidade, exótica ou nativa (Quadro 1), Para dados estatísticos foram calculadas as espécies em porcentagem de exótica e nativa, ou seja, foram calculadas as espécimes exótica e nativas foram multiplicados por x, multiplicado por $100 \%$ e posteriormente dividiu-se em nativas e exóticas (Figura 1), esse calculo não foi usado para a quantidade de cada espécime.

\section{RESULTADOS E DISCUSSÕES}

Após a identificação das espécies, essas foram catalogadas em forma de cartilha, aonde foi possível observar as características de cada espécie conforme a quadro 1 do anexo 1. 
As mudas identificadas dentro do Horto Florestal totalizaram 84 espécies diferentes, sendo que 42 espécies apresentaram-se como exóticas e 42 nativas, onde $50 \%$ exótica/nativa foram identificadas, isso se dá por que a maioria das sementes e mudas são provenientes de compensação ambiental, doações e compras realizadas pela secretaria, e com isso não se tem uma produção de mudas $100 \%$ nativa.

Outro fator importante a se salientar é sobre a identificação das espécies exóticas, poucos estudos tem-se a respeito delas e com isso acaba sendo difícil a identificação de forma confiável dessas espécies. As espécies que são mais utilizadas na arborização urbana conforme dados coletados na Secretaria do Meio Ambiente do Município são: Oiti, Quaresmeira, Resedá, Aroeira Salsa, Acácia amarela, Alfeneiro, Ipê de Jardim, Ipê branco e amarelo, Magnólia, Flamboyant mirim, Pataca (árvore do dinheiro), Jambo, Pata-de-vaca.

De acordo com Silva (2000), é comum que poucas espécies representem a maior parte da arborização, como o ocorrido neste estudo, o que não é adequado. Alguns trabalhos também verificaram uma concentração maior de indivíduos distribuídos num pequeno número de espécies, como o município de Piracicaba - SP (LIMA et al., 1994),

Segundo Toledo Filho e Parente (1988), é de suma importância se ter heterogeneidade das espécies para a implantação de uma arborização urbana, pois além de ser uma forma de difundir e valorizar a flora brasileira também protege e favorece a sobrevivência de animais que constituem importantes elementos do equilíbrio ecológico. Graziano (1994) aponta a importância da variabilidade de espécies em arborização de um bairro ou cidade.

Neste trabalho observou uma baixa intensidade de plantio de espécies nativas e Lorenzi (2002) aponta que a utilização de espécies nativas é insignificante considerando-se a riqueza de nossa flora. Desde o início de nossa colonização a utilização de espécies exóticas foi a grande responsável pelo desaparecimento de muitos dos animais dos centros urbanos.

A grande quantidade de plantas exóticas identificadas e utilizadas na arborização do município de Presidente Prudente corrobora com estudos de Ziller (2001) que aponta o potencial de espécies exóticas de alterar sistemas naturais é tão grande que as plantas invasoras são, hoje, a segunda maior ameaça mundial à biodiversidade perdendo somente para a destruição direta do homem. 
Assim, quando existe um plantio de árvores em meio urbano observa-se que estas estarão submetidas a condições adversas das que são oferecidas em ambiente natural, portanto é imprescindível utilizar espécies que ocorram naturalmente na região em que a árvore será plantada para que seu e desenvolvimento, adaptabilidade e crescimento não sejam afetados. Segundo Reis et al. (2003), projetos de arborização urbana podem criar modelos com réplicas dos modelos vegetacionais regionais, como agrupamentos arbóreos com grande número de epífitas e lianas imitando os extratos das florestas, e desta forma, expressando a biodiversidade, que deve ser um valor cultural reconhecido dentro do meio urbano.

\section{CONSIDERAÇÕES FINAIS}

Observa-se que através da identificação das espécies do Horto Florestal, é possível saber quais espécies podem ser doadas e plantadas, servindo assim como base para futuros trabalhos de gestão do viveiro.

A cartilha serve como etapa inicial para indicações de espécies ao plantio urbano, além de ser um material de apoio para futuras indicações de plantios através dos profissionais que trabalham nesse local, bem como apontamentos de forma mais concisa da espécie para o espaço que se pretende plantar (adequação), pois através das informações obtidas na cartilha, os técnicos bem como a população, terá um embasamento do manejo para cada espécie, facilitando assim o plantio e cuidados posteriores.

\section{REFERÊNCIAS}

ÁRVORES DO BRASIL. Disponível em: <http://www.arvores.brasil.nom.br/>.Acesso em: dezembro de 2014.

BIONDI, D.; LEAL, L.; COBALCHINI, J.L. Tratamentos silviculturais em mudas de Allophylusedulis (A. St.- Hil., Cambess. \& A. Juss.) Radlk. para arborização de ruas. Floresta, Curitiba, v.37, n.3, p.437-444, 2007.

BOIN, M. N. Carta de risco à erosão pluvial no Oeste paulista; 2000. Disponível em $<$ http//www.sigrh.sp.gov.br/cgibin/sigrh_home_colegiado.exe?COLEGIADO=CRH\%2FCBHPP\&TEMA $=$ RELATORIO> Acesso em: 28 set. 2013. 
DANTAS, I. C.; SOUZA, C.M. C. Arborização urbana na cidade de Campina Grande-PB:Inventário e suas espécies. Revista de Biologia e Ciências da Terra.v.4, n.2, 2004.

FLORA DIGITAL DO RIO GRANDE DO SUL E DE SANTA CATARINA. Disponível em: <http://ufrgs.br/floradigital>Acesso em 28 de dezembro de 2014.

FRANCISCO, C. F. Análise ambiental e conseqüências do desmatamento no município de Presidente Prudente no período de 1917 a 1986. Dissertação (mestrado em geografia), UNESP IGCE. Rio Claro Claro, 1989.

GOMES, Marcos Antônio Silvestre; AMORIM, Margarete Cristiane de Costa Trindade. Arborização e conforto térmico no espaço urbano: Estudo de caso nas praças públicas de Presidente Prudente (SP). Caminhos de Geografia 7, 2003, p.94-106.

GRAZIANO, T. T. Viveiros Municipais. Departamento de Horticultura - FCAVJ - UNESP. Notas de Aula, 1994.

HERBÁRIO DO DEPARTAMENTO DE CIÊNCIAS FLORESTAIS - Universidade Federal de Santa Maria. Disponível em: <http://w3.ufsm.br/herbarioflorestal/index.php>Acesso em 28 de dezembro de 2014.

INSTITUTO BRASILEIRO DE FLORESTAS - Loja de sementes. Disponível em:<http://ibflorestas.org.br/loja/sementes>. Acesso em: dezembro de 2014.

LIMA, A. M. L. P.; COUTO, H. T. Z.; ROXO, J. L. C. Análise de espécies mais frequentes da arborização viária, na zona urbana central do município de Piracicaba/SP. In: Congresso Brasileiro de Arborização Urbana. São Luis: Sociedade Brasileira de Arborização Urbana, p.555-573, 1994.

LORENZI, Harri. Árvores Brasileiras: Manual de Identificação e Cultivo de Plantas Arbóreas Nativas do Brasil. Vol 1 - 5. ed. Nova Odessa, SP. 348p.

LORENZI, Harri. Árvores Brasileiras: Manual de Identificação e Cultivo de Plantas Arbóreas Nativas do Brasil. Vol 2 - 3. ed. Nova Odessa, SP. 384p.

LORENZI, Harri. Árvores Brasileiras: Manual de Identificação e Cultivo de Plantas Arbóreas Nativas do Brasil. Vol 3 - 1. ed. Nova Odessa, SP. 384p.

LORENZI, Harri. Árvores Exóticas no Brasil: madeireiras, ornamentais e aromáticas. Nova Odessa, SP. 391 p.MONTEIRO, C. A. de F. A dinâmica climática e as chuvas no Estado de São Paulo. IGEOG/USP, São Paulo, 1973.

LORENZI, H. Árvores Brasileiras: manual de identificação e cultivo de plantas arbóreas nativas do Brasil. Editora PlantarumLtda, v. 1., 2002., 384 p.

MONTEIRO, C. A. de F. A dinâmica climática e as chuvas no Estado de São Paulo. IGEOG/USP, São Paulo, 1973.0 JARDINEIRO. Disponível em: <http://www.jardineiro.net/>. Acesso em: $08 \mathrm{dez}$. 2014

TOLEDO,D.V.; PARENTE,P.R. Arborização urbana com essências nativas. Boletim Técnico do Instituto Florestal, v.42, p.19-31, mai.1988.

REIS, A; ANJOS, A.; LESSA, A. P.; BECCHARA, F. C. Critérios para seleção de espécies na arborização urbana ecológica.Sellowia 53-55: 51-67, 2003.

ROTTA, E; CARVALHO, L. C.; ZONTA, B. M.; Manual de Prática de Coleta e Herborização de Material Botânico. Embrapa Florestas Colombo, PR 2008. Disponível em: <http://ainfo.cnptia.embrapa.br/digital/bitstream/CNPF-2009-09/44599/1/Doc173.pdf/> Acesso em: 18 Jan. 2015. 
SILVA, J. R. M. Análise e Avaliação das Erradicações na arborização urbana da cidade do Recife: percepção coletiva e apropriação social. In: Congresso Brasileiro de Arborização Urbana. Rio de Janeiro, Sociedade Brasileira de Arborização Urbana, 2000.

ZILLER, S. R. Plantas Exóticas Invasoras: a ameaça da contaminação biológica. Revista Ciência Hoje, n.178, 2001. Disponível em: http://www.cienciahoje.uol.com.br. Acesso em: 05 Fev. 2015.

\section{ANEXOS}

\section{Anexo 1}

Quadro 1- Catalogação das espécies de mudas contidas no Horto Florestal. 


\section{Periódica Eletranica

\begin{tabular}{|c|c|}
\hline \multicolumn{2}{|c|}{ Espécie 1 - EXÓTICA } \\
\hline Nome popular & Acácia negra \\
\hline Nome científico & Acaciamearnsi \\
\hline Altura & 15 a $20 \mathrm{~m}$ \\
\hline Floração & julho a outubro \\
\hline Luminosidade & Sol Pleno \\
\hline \multicolumn{2}{|c|}{ Espécie 2 - NATIVA } \\
\hline Nome popular & Acácia mimosa \\
\hline Nome científico & Acaciapodalyriifolia \\
\hline Altura & $7,0 \mathrm{~m}$ \\
\hline Floração & Junho \\
\hline Luminosidade & Sol pleno \\
\hline \multicolumn{2}{|c|}{ Espécie 3 - EXÓTICA } \\
\hline Nome popular & Acácia trinervis \\
\hline Nome científico & Acacialongifolia \\
\hline Altura & $11 \mathrm{~m}$ \\
\hline Floração & Janeiro a Março \\
\hline Luminosidade & Sol pleno \\
\hline \multicolumn{2}{|c|}{ Espécie 4 - EXÓTICA } \\
\hline Nome popular & Acalifa \\
\hline Nome científico & Acalyphawilkesiana \\
\hline Altura & $1,8 \mathrm{~m}$ \\
\hline Floração & Julho a setembro \\
\hline Luminosidade & Luz Difusa, Meia Sombra \\
\hline \multicolumn{2}{|c|}{ Espécie 5- EXÓTICA } \\
\hline Nome popular & Alfeneiro \\
\hline Nome científico & Ligustrumlucidum \\
\hline Altura & $7 \mathrm{a} 10 \mathrm{~m}$ \\
\hline Floração & Primavera/ verão \\
\hline Luminosidade & Sol pleno \\
\hline \multicolumn{2}{|c|}{ Espécie6- EXÓTICA } \\
\hline Nome popular & Amora \\
\hline Nome científico & Morus nigra \\
\hline Altura & $2 \mathrm{~m}$ \\
\hline Floração & Outubro a novembro \\
\hline Luminosidade & Sol pleno \\
\hline \multicolumn{2}{|c|}{ Espécien7- NATIVA } \\
\hline Nome popular & Angico vermelho \\
\hline Nome científico & Parapiptadeniarigida \\
\hline Altura & $35 \mathrm{~m}$ \\
\hline Floracão & novembro a dezembro \\
\hline Luminosidade & Ensolarado \\
\hline \multicolumn{2}{|c|}{ Espécie 8-NATIVA } \\
\hline Nome popular & Angico branco \\
\hline Nome científico & Anadenanthera colubrina \\
\hline Altura & 12 a $15 \mathrm{~m}$ \\
\hline Floracão & Setembro \\
\hline Luminosidade & Angico branco \\
\hline \multicolumn{2}{|c|}{ Espécie9- NATIVA } \\
\hline Nome popular & Araucária \\
\hline Nome científico & Araucariaangustifolia \\
\hline Altura & 10 a $35 \mathrm{~m}$ \\
\hline Floração & Primavera, Outono, Inverno. \\
\hline Luminosidade & Pleno sol \\
\hline \multicolumn{2}{|c|}{ Espécie10- NATIVA } \\
\hline Nome popular & Aroeira brava \\
\hline Nome científico & Lithraeamolleoides \\
\hline
\end{tabular}




\section{Periódica Eletranica

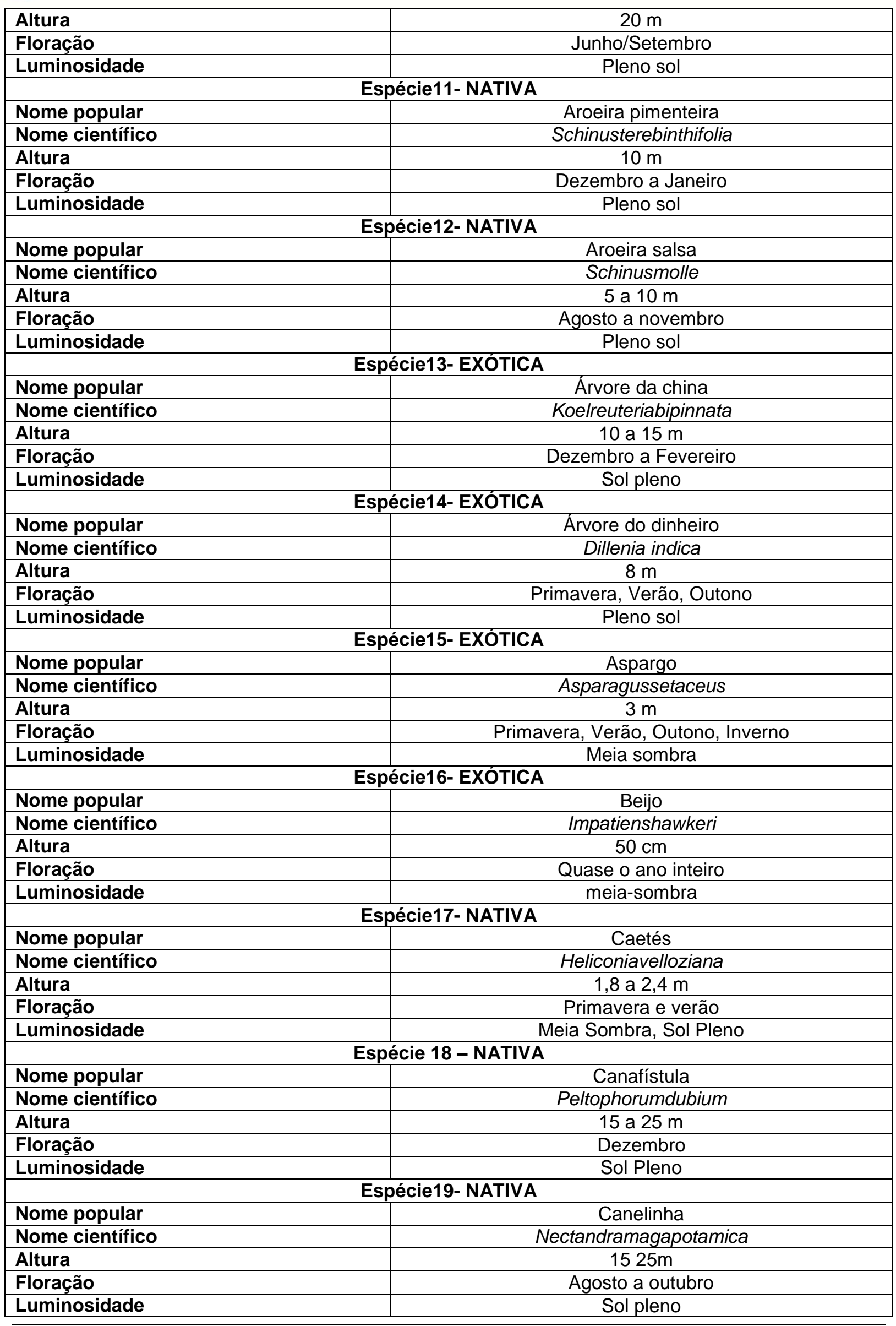




\section{Periódica Eletranica

\begin{tabular}{|c|c|}
\hline \multicolumn{2}{|c|}{ Espécie 20- EXÓTICA } \\
\hline Nome popular & Citronela \\
\hline Nome científico & Cymbopogonwinterianus \\
\hline Altura & $0,80 \mathrm{a} 1,20 \mathrm{~m}$ \\
\hline Floração & Primavera \\
\hline Luminosidade & Pleno sol \\
\hline \multicolumn{2}{|c|}{ Espécie 21- EXÓTICA } \\
\hline Nome popular & Comigo ninguém pode \\
\hline Nome científico & Dieffenbachiaamoena \\
\hline Altura & 20 a $50 \mathrm{~cm}$ \\
\hline Floração & Verão \\
\hline Luminosidade & Meia sombra \\
\hline \multicolumn{2}{|c|}{ Espécie 22- EXÓTICA } \\
\hline Nome popular & Chapéu de sol \\
\hline Nome científico & Terminaliacatappa \\
\hline Altura & 9 a $12 \mathrm{~m}$ \\
\hline Floração & Primavera \\
\hline Luminosidade & Pleno sol \\
\hline \multicolumn{2}{|c|}{ Espécie 23- EXÓTICA } \\
\hline Nome popular & Cheflera \\
\hline Nome científico & Scheffleraarboricola \\
\hline Altura & 3,0 a $3,6 \mathrm{~m}$ \\
\hline Floração & Primavera \\
\hline Luminosidade & Meia sombra \\
\hline \multicolumn{2}{|c|}{ Espécie24- NATIVA } \\
\hline Nome popular & Clúsia \\
\hline Nome científico & Clusiafluminensis \\
\hline Altura & $4 \mathrm{a} 6 \mathrm{~m}$ \\
\hline Floração & Primavera e verão \\
\hline Luminosidade & Meia sombra a pleno sol \\
\hline \multicolumn{2}{|c|}{ Espécie25- EXÓTICA } \\
\hline Nome popular & Cróton \\
\hline Nome científico & Codiaeumvariegatum \\
\hline Altura & 2 a $3 \mathrm{~m}$ \\
\hline Floração & Agosto \\
\hline Luminosidade & Sol pleno \\
\hline \multicolumn{2}{|c|}{ Espécie 26- EXÓTICA } \\
\hline Nome popular & Dracena vermelha \\
\hline Nome científico & Cordylineterminalis \\
\hline Altura & 1,50 a $2,80 \mathrm{~m}$ \\
\hline Floração & Ano inteiro \\
\hline Luminosidade & Sol pleno e Meia-sombra \\
\hline \multicolumn{2}{|c|}{ Espécie 27- EXÓTICA } \\
\hline Nome popular & Dracena mexicana \\
\hline Nome científico & Dracaenamarginata \\
\hline Altura & $2 \mathrm{a} 4 \mathrm{~m}$ \\
\hline Floração & Verão \\
\hline Luminosidade & Pleno sol \\
\hline \multicolumn{2}{|c|}{ Espécie 28 - NATIVA } \\
\hline Nome popular & Embaúba \\
\hline Nome científico & Cecropiapachystachya \\
\hline Altura & 4 a $8 \mathrm{~m}$ \\
\hline Floração & Setembro \\
\hline Luminosidade & Pleno sol \\
\hline \multicolumn{2}{|c|}{ Espécie 29 - EXÓTICA } \\
\hline Nome popular & Ficus \\
\hline Nome científico & Ficusbenjamina \\
\hline
\end{tabular}




\begin{tabular}{|c|c|}
\hline Altura & Até 12 metros \\
\hline Floração & Primavera \\
\hline Luminosidade & Meia sombra/sol pleno \\
\hline \multicolumn{2}{|c|}{ Espécie 30 - NATIVA } \\
\hline Nome popular & Flamboyant mirim \\
\hline Nome científico & Caesalpiniapulcherrima \\
\hline Altura & $3-4$ metros \\
\hline Floração & Setembro a abril \\
\hline Luminosidade & Sol pleno \\
\hline \multicolumn{2}{|c|}{ Espécie 31 - NATIVA } \\
\hline Nome popular & Guajuvira \\
\hline Nome científico & Cordia americana \\
\hline Altura & $10-25$ metros \\
\hline Floração & Julho a outubro \\
\hline Luminosidade & Meia sombra/ sol pleno \\
\hline \multicolumn{2}{|c|}{ Espécie 32 - NATIVA } \\
\hline Nome popular & Graviola \\
\hline Nome científico & Annonamuricata \\
\hline Altura & $5-10$ metros \\
\hline Floração & Setembro a janeiro \\
\hline Luminosidade & Sol pleno \\
\hline \multicolumn{2}{|c|}{ Espécie 33 - EXÓTICA } \\
\hline Nome popular & Grevilha \\
\hline Nome científico & Grevillea robusta \\
\hline Altura & $20-24$ metros \\
\hline Floração & Primavera e Inverno \\
\hline Luminosidade & Sol pleno \\
\hline \multicolumn{2}{|c|}{ Espécie 34 - NATIVA } \\
\hline Nome popular & Helicônia papagaio \\
\hline Nome científico & Heliconiapsittacorum \\
\hline Altura & Varia de 0,4 até $1,8 \mathrm{~m}$ \\
\hline Floração & Verão \\
\hline Luminosidade & Meia sombra \\
\hline \multicolumn{2}{|c|}{ Espécie 35 - EXÓTICA } \\
\hline Nome popular & Hibisco \\
\hline Nome científico & Hibiscus rosa-sinensis \\
\hline Altura & Varia de 0,3 até $1,8 \mathrm{~m}$ \\
\hline Floração & Todo ano \\
\hline Luminosidade & Meia sombra/sol pleno \\
\hline \multicolumn{2}{|c|}{ Espécie 36 - NATIVA } \\
\hline Nome popular & Ingá \\
\hline Nome científico & Inga vera \\
\hline Altura & $5-10$ metros \\
\hline Floração & Agosto á setembro \\
\hline Luminosidade & Pleno sol \\
\hline \multicolumn{2}{|c|}{ Espécie 37 - NATIVA } \\
\hline Nome popular & Ipê amarelo \\
\hline Nome científico & Handroanthuschrysotricha \\
\hline Altura & Até 10 metros \\
\hline Floração & Inverno \\
\hline Luminosidade & Pleno sol \\
\hline \multicolumn{2}{|c|}{ Espécie 38 - EXÓTICA } \\
\hline Nome popular & Ipê amarelo de jardim \\
\hline Nome científico & Tecomastans \\
\hline Altura & 4- 6 metros \\
\hline Floração & Primavera e verão \\
\hline Luminosidade & Pleno sol \\
\hline
\end{tabular}




\section{Periódica Eletranica

\begin{tabular}{|c|c|}
\hline \multicolumn{2}{|c|}{ Espécie 39 - NATIVA } \\
\hline Nome popular & Ipê branco \\
\hline Nome científico & Handroanthusroseo-alba \\
\hline Altura & $7-16$ metros \\
\hline Floração & Agosto a novembro \\
\hline Luminosidade & Pleno sol \\
\hline \multicolumn{2}{|c|}{ Espécie 40 - NATIVA } \\
\hline Nome popular & Ipê rosa \\
\hline Nome científico & Handroanthusavellanedae \\
\hline Altura & $20-35$ metros \\
\hline Floração & Julho a agosto \\
\hline Luminosidade & Pleno sol \\
\hline \multicolumn{2}{|c|}{ Espécie 41 - NATIVA } \\
\hline Nome popular & Ipê roxo \\
\hline Nome científico & Handroanthusheptaphyllus \\
\hline Altura & Até 30 metros \\
\hline Floração & Junho a setembro \\
\hline Luminosidade & Pleno sol \\
\hline \multicolumn{2}{|c|}{ Espécie 42 - EXÓTICA } \\
\hline Nome popular & Jaca \\
\hline Nome científico & Artocarpusheterophyllus \\
\hline Altura & $8-25$ metros \\
\hline Floração & Novembro e dezembro \\
\hline Luminosidade & Pleno sol \\
\hline \multicolumn{2}{|c|}{ Espécie 43 - EXÓTICA } \\
\hline Nome popular & Jambo \\
\hline Nome científico & Syzygium jambos \\
\hline Altura & $10-15$ metros \\
\hline Floração & Julho a novembro \\
\hline Luminosidade & Pleno sol \\
\hline \multicolumn{2}{|c|}{ Espécie 44 - EXÓTICA } \\
\hline Nome popular & Jasmim \\
\hline Nome científico & Jasminumpolyanthum \\
\hline Altura & $3,6-4,7$ metros \\
\hline Floração & Outono, inverno/primavera \\
\hline Luminosidade & Meia sombra/pleno sol \\
\hline \multicolumn{2}{|c|}{ Espécie 45 - NATIVA } \\
\hline Nome popular & Jenipapo \\
\hline Nome científico & Genipa americana \\
\hline Altura & $8-14$ metros \\
\hline Floração & Novembro, julho e agosto \\
\hline Luminosidade & Meia sombra/pleno sol \\
\hline \multicolumn{2}{|c|}{ Espécie 46 - NATIVA } \\
\hline Nome popular & Jequitibás \\
\hline Nome científico & Carinianalegalis \\
\hline Altura & $30-50$ metros \\
\hline Floracão & Dezembro a fevereiro \\
\hline Luminosidade & Sombra \\
\hline \multicolumn{2}{|c|}{ Espécie 47 - EXÓTICA } \\
\hline Nome popular & João bolão \\
\hline Nome científico & Syzigiumjambolanum \\
\hline Altura & $10-15$ metros \\
\hline Floração & Primavera \\
\hline Luminosidade & Pleno sol \\
\hline \multicolumn{2}{|c|}{ Espécie 48 - EXÓTICA } \\
\hline Nome popular & Magnólia \\
\hline Nome científico & Magnoliagrandiflora \\
\hline
\end{tabular}




\begin{tabular}{|c|c|}
\hline Altura & $25-30$ metros \\
\hline Floração & Maio a agosto \\
\hline Luminosidade & Pleno sol \\
\hline \multicolumn{2}{|c|}{ Espécie 49 - NATIVA } \\
\hline Nome popular & Mamica de porca \\
\hline Nome científico & Zanthoxylumrhoifolium \\
\hline Altura & $6-12$ metros \\
\hline Floração & Outubro a novembro \\
\hline Luminosidade & Sombra \\
\hline \multicolumn{2}{|c|}{ Espécie 50 - EXÓTICA } \\
\hline Nome popular & Manga \\
\hline Nome científico & Mangifera indica \\
\hline Altura & $12-30$ metros \\
\hline Floração & Junho e julho \\
\hline Luminosidade & Pleno sol \\
\hline \multicolumn{2}{|c|}{ Espécie 51 - EXÓTICA } \\
\hline Nome popular & Mini resedá \\
\hline Nome científico & Sweetmignonette \\
\hline Altura & Até 6 metros \\
\hline Floração & Verão \\
\hline Luminosidade & Pleno sol \\
\hline \multicolumn{2}{|c|}{ Espécie 52 - NATIVA } \\
\hline Nome popular & Monguba \\
\hline Nome científico & Pachiraaquatica \\
\hline Altura & $7-18$ metros \\
\hline Floração & Novembro \\
\hline Luminosidade & Pleno sol \\
\hline \multicolumn{2}{|c|}{ Espécie 53 - EXÓTICA } \\
\hline Nome popular & Moringa \\
\hline Nome científico & Moringa oleifera \\
\hline Altura & Até 12 metros \\
\hline Floração & Todo o ano \\
\hline Luminosidade & Pleno sol \\
\hline \multicolumn{2}{|c|}{ Espécie 54 - EXÓTICA } \\
\hline Nome popular & Murta \\
\hline Nome científico & Murrayapaniculata \\
\hline Altura & Até 7 metros \\
\hline Floração & Todo o ano \\
\hline Luminosidade & Meia sombra/pleno sol \\
\hline \multicolumn{2}{|c|}{ Espécie 55 - EXÓTICA } \\
\hline Nome popular & $\mathrm{Nim}$ \\
\hline Nome científico & Azadirachta indica \\
\hline Altura & Até 30 metros \\
\hline Floração & Fevereiro a maio \\
\hline Luminosidade & Pleno sol \\
\hline \multicolumn{2}{|c|}{ Espécie 56 - EXÓTICA } \\
\hline Nome popular & Noni \\
\hline Nome científico & Morindacitrifolia \\
\hline Altura & Até 9 metros \\
\hline Floração & junho a agosto \\
\hline Luminosidade & Meia sombra/pleno sol \\
\hline \multicolumn{2}{|c|}{ Espécie 57 - NATIVA } \\
\hline Nome popular & Oiti \\
\hline Nome científico & Licania tomentosa \\
\hline Altura & 6 a $12 \mathrm{~m}$ \\
\hline Floração & Junho a agosto \\
\hline Luminosidade & Sol pleno \\
\hline
\end{tabular}




\section{Periódica Eletranica

\begin{tabular}{|c|c|}
\hline \multicolumn{2}{|c|}{ Espécie 58 - NATIVA } \\
\hline Nome popular & Paineira \\
\hline Nome científico & Ceibaspeciosa (A. St.-Hil.) Ravenna \\
\hline Altura & $15-30 \mathrm{~m}$ \\
\hline Floração & fevereiro a abril \\
\hline Luminosidade & Sol pleno \\
\hline \multicolumn{2}{|c|}{ Espécie 59 - EXÓTICA } \\
\hline Nome popular & Palmeira anã \\
\hline Nome científico & Chamaeropshumilis \\
\hline Altura & 1,5 a 3 metros \\
\hline Floração & Abril-junho \\
\hline Luminosidade & Sol pleno \\
\hline \multicolumn{2}{|c|}{ Espécie 60 - EXÓTICA } \\
\hline Nome popular & Palmeira areca \\
\hline Nome científico & Dypsislutescens \\
\hline Altura & 3 até 9 metros \\
\hline Floração & Ano todo \\
\hline Luminosidade & Sol pleno/ meia sombra \\
\hline \multicolumn{2}{|c|}{ Espécie 61 - EXÓTICA } \\
\hline Nome popular & Palmeira fenix \\
\hline Nome científico & Phoenix roebelenii \\
\hline Altura & 1,2 a $3,6 \mathrm{~m}$ \\
\hline Floração & Ano todo \\
\hline Luminosidade & Sol pleno/ meia sombra \\
\hline \multicolumn{2}{|c|}{ Espécie 62 - EXÓTICA } \\
\hline Nome popular & Palmeira imperial \\
\hline Nome científico & Roystonea regia \\
\hline Altura & 18 a $45 \mathrm{~m}$ \\
\hline Floração & Verão e primavera \\
\hline Luminosidade & Sol pleno \\
\hline \multicolumn{2}{|c|}{ Espécie 63 - EXÓTICA } \\
\hline Nome popular & Palmeira laca \\
\hline Nome científico & Cyrtostachys renda \\
\hline Altura & 6 até $12 \mathrm{~m}$ \\
\hline Floração & Todo ano \\
\hline Luminosidade & Meia sombra/sol pleno \\
\hline \multicolumn{2}{|c|}{ Espécie 64 - EXÓTICA } \\
\hline Nome popular & Palmeira latanea \\
\hline Nome científico & Latanialontaroides \\
\hline Altura & $8-10$ metros \\
\hline Floração & Inverno \\
\hline Luminosidade & Pleno sol/meia sombra \\
\hline \multicolumn{2}{|c|}{ Espécie 65 - EXÓTICA } \\
\hline Nome popular & Palmeira ráfia \\
\hline Nome científico & Rhapis excelsa \\
\hline Altura & 1,2 a $3 \mathrm{~m}$ \\
\hline Floração & Todo o ano \\
\hline Luminosidade & Sol pleno/meia sombra \\
\hline \multicolumn{2}{|c|}{ Espécie 66 - EXÓTICA } \\
\hline Nome popular & Pata de vaca \\
\hline Nome científico & Bauhiniaforficata \\
\hline Altura & 6 a 12 metros \\
\hline Floração & Julho a outubro \\
\hline Luminosidade & Pleno sol \\
\hline \multicolumn{2}{|c|}{ Espécie 67 - NATIVA } \\
\hline Nome popular & Pau Brasil \\
\hline Nome científico & Caesalpiniaechinata \\
\hline
\end{tabular}




\begin{tabular}{|c|c|}
\hline Altura & $7-16$ metros \\
\hline Floração & Setembro e outubro \\
\hline Luminosidade & Pleno sol \\
\hline \multicolumn{2}{|c|}{ Espécie 68 - NATIVA } \\
\hline Nome popular & Pau d' alho \\
\hline Nome científico & Gallesiaintegrifolia \\
\hline Altura & 10 a 25 metros \\
\hline Floração & Abril a junho \\
\hline Luminosidade & Pleno sol \\
\hline \multicolumn{2}{|c|}{ Espécie 69 - NATIVA } \\
\hline Nome popular & Pau ferro \\
\hline Nome científico & Caesalpiniaferrea \\
\hline Altura & 15 a 30 metros \\
\hline Floração & Dezembro a fevereiro \\
\hline Luminosidade & Sol pleno \\
\hline \multicolumn{2}{|c|}{ Espécie 70 - NATIVA } \\
\hline Nome popular & Pau formiga \\
\hline Nome científico & Triplaris americana \\
\hline Altura & Acima de 12 metros \\
\hline Floração & Inverno e iníco da primavera \\
\hline Luminosidade & Sol pleno \\
\hline \multicolumn{2}{|c|}{ Espécie 71 - NATIVA } \\
\hline Nome popular & Pingo de ouro \\
\hline Nome científico & Durantaerectaaurea \\
\hline Altura & 3,6 a 6 metros \\
\hline Floração & Primavera verão \\
\hline Luminosidade & Sol pleno \\
\hline \multicolumn{2}{|c|}{ Espécie 72 - NATIVA } \\
\hline Nome popular & Piriquito \\
\hline Nome científico & Alternantheraficoidea \\
\hline Altura & 0,1 a 0,3 metros \\
\hline Floração & Verão \\
\hline Luminosidade & Sol pleno \\
\hline \multicolumn{2}{|c|}{ Espécie 73 - NATIVA } \\
\hline Nome popular & Pitanga \\
\hline Nome científico & Eugenia uniflora \\
\hline Altura & 1,8 a 2 metros \\
\hline Floração & Agosto a dezembro \\
\hline Luminosidade & Sol pleno \\
\hline \multicolumn{2}{|c|}{ Espécie 74 - NATIVA } \\
\hline Nome popular & Primavera \\
\hline Nome científico & Bougainvillea glabra \\
\hline Altura & 4,7 a 6 metros \\
\hline Floração & Primavera a outono \\
\hline Luminosidade & Sol pleno \\
\hline \multicolumn{2}{|c|}{ Espécie 75 - NATIVA } \\
\hline Nome popular & Quaresmeira \\
\hline Nome científico & Tibouchina granulosa \\
\hline Altura & Acima de 9 metros \\
\hline Floração & Outono e primavera \\
\hline Luminosidade & Sol pleno \\
\hline \multicolumn{2}{|c|}{ Espécie 76 - EXÓTICA } \\
\hline Nome popular & Resedá \\
\hline Nome científico & Lagerstroemia indica \\
\hline Altura & 3,6 a 9 metros \\
\hline Floração & Primavera e verão \\
\hline Luminosidade & Pleno sol \\
\hline
\end{tabular}




\section{Periódica Eletrânica

\begin{tabular}{|c|c|}
\hline \multicolumn{2}{|c|}{ Espécie 77 - EXÓTICA } \\
\hline Nome popular & Rubia \\
\hline Nome científico & Rubia agostinhoi \\
\hline Altura & $50 \mathrm{~cm}$ \\
\hline Floração & Abril a junho \\
\hline Luminosidade & Pleno sol \\
\hline \multicolumn{2}{|c|}{ Espécie 78 - NATIVA } \\
\hline Nome popular & Saboneteira \\
\hline Nome científico & Sapindussaponaria \\
\hline Altura & Até 12 metros \\
\hline Floração & Julho a agosto \\
\hline Luminosidade & Sol pleno \\
\hline \multicolumn{2}{|c|}{ Espécie 79 - NATIVA } \\
\hline Nome popular & Sangra d' água \\
\hline Nome científico & Crotonurucurana \\
\hline Altura & 3 a 15 metros \\
\hline Floração & Janeiro \\
\hline Luminosidade & Sol pleno \\
\hline \multicolumn{2}{|c|}{ Espécie 80 - NATIVA } \\
\hline Nome popular & Sapucaia \\
\hline Nome científico & Lecythispisonis \\
\hline Altura & Acima de 12 metros \\
\hline Floração & Primavera \\
\hline Luminosidade & Sol pleno \\
\hline \multicolumn{2}{|c|}{ Espécie 81 - NATIVA } \\
\hline Nome popular & Seringueira \\
\hline Nome científico & Hevea brasiliensis \\
\hline Altura & 20 a 30 metros \\
\hline Floração & Setembro a fevereiro \\
\hline Luminosidade & Sol pleno \\
\hline \multicolumn{2}{|c|}{ Espécie 82 - NATIVA } \\
\hline Nome popular & Sibipiruna \\
\hline Nome científico & Caesalpiniapeltophoroides \\
\hline Altura & Acima de 6 metros \\
\hline Floração & Setembro e outubro \\
\hline Luminosidade & Sol pleno \\
\hline \multicolumn{2}{|c|}{ Espécie 83 - NATIVA } \\
\hline Nome popular & Tamanqueira \\
\hline Nome científico & Aegiphilasellowiana \\
\hline Altura & 2 a 7 metros \\
\hline Floração & Dezembro a janeiro e setembro (possível) \\
\hline Luminosidade & Sol pleno \\
\hline \multicolumn{2}{|c|}{ Espécie 84 - EXÓTICA } \\
\hline Nome popular & Tipuana \\
\hline Nome científico & Tipuanatipu \\
\hline
\end{tabular}




\begin{tabular}{|l|c|}
\hline Altura & Acima de 12 metros \\
\hline Floração & Primavera e Final do inverno \\
\hline Luminosidade & Sol pleno \\
\hline
\end{tabular}

